\title{
ДОСЛІДЖЕННЯ ЕФЕКТИВНОСТІ ФУНКЦОНУВАННЯ АСОЗ ПТЛ ПРИЙОМУ ЗЕРНА 3 ЗАЛІЗНИЧНОГО ТРАНСПОРТУ НА ЕЛЕВАТОРІ «МКХП ОРЕКСІМ» М. МИКОЛАЇВ
}

\author{
Кір'язов І. М. ${ }^{1}$, Шестопалов С. В. ${ }^{2}$, Степанов М. Т. ${ }^{3}$, Хобін В. А. ${ }^{4}$
}

Одеська національна академія харчових технологій, Одеса, Україна

ORCID: ${ }^{3}$ https://orcid.org/0000-0003-1297-5537, ${ }^{4}$ https://orcid.org/0000-0003-0238-8371

E-mail: ${ }^{1}$ ivan.kiryazov@ @e.ua, ${ }^{2}$ stanislav.shestopalov@ se.ua, ${ }^{3}$ stepanov197818@gmail.com, ${ }^{4}$ khobin@onaft.edu.ua

Copyright $(\mathcal{C} 2020$ by author and the journal "Automation of technological and business - processes.

This work is licensed under the Creative Commons Attribution International License (CC BY).

http://creativecommons.org/licanses/by/4.0

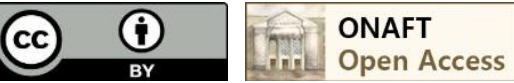

\section{DOI: https://doi.org/10.15673/atbp.v12i2.1801}

\begin{abstract}
Анотація. У статті розглядаються результати функціонування в виробничих умовах автоматизованої системи оптимізації завантаження поточно транспортних ліній прийому зерна з залізничного транспорту на елеваторі «МКХП Орексім» у місті Миколаїв. Система призначена для формування потоку зерна одночасно з декількох вагонів розташованих на різних коліях та стабілізаџї продуктивності загального потоку зерна на заданому рівні, підвищення продуктивності та виведення ї̈ на максимально досяжну з урахуванням паспортних характеристик обладнання поточно транспортних ліній, зниження енерговитрат на перевантаження, запобігання аварійних ситуачій, пов'язаних з завалами зерна в баммаках норій. Автоматизована система оптимізації завантаження реалізує технологіï Leffol \& Sепитас які запатентовані SE Group International. Програмне забезпечення системи інтегровано в програмне забезпечення автоматизованої системи керування технологічними процесами елеватора $i$ дозволяє оператору задавати компоненти потоку прийнятого зерна та початкову продуктивність поточно транспортних ліній, здійснювати вибір режиму керування їх завантаженням та вибір режиму завдання продуктивності поточно транспортних ліній в поточній технологічної ситуації, контролювати функціонування автоматизованої системи оптимізації завантаження. Результати порівняльного аналізу ефективності управління завантаженням при прийомі зерна з залізничних вагонів оператором «вручну» $i$ з використанням автоматизованої системи оптимізаиії завантаження, проведені в 2020 рочі, показали наступне: середній час прийому зерна 3 залізничних вагонів з урахуванням простоїв зменшилось на 15\%; середня продуктивність прийому зерна без урахування простоїв збільшилася на 10\%. При цьому аварійних зупинок транспортного обладнання поточно транспортних ліній пов'язаних з завалами зерна протягом виробничих випробувань та опитної експлуатації не виникало.
\end{abstract}

Abstract. The article considers the results of functioning in production conditions of the automated loading optimization system of the flow-transport lines of reception of grain from railway transport on the elevator "NKHP Orexim" in the city of Nikolaev. The system is designed to generate the grain flow simultaneously from several cars located on different tracks and stabilize the productivity of the total grain flow at a given level, increase productivity and bring it to the maximum achievable taking into account the passport characteristics of flow-transport lines equipment, reduce energy consumption for overload, prevent emergency situations associated with grain debris in the boots of norias. Loading optimization system implements Leffol \& Senumac technologies patented by SE Group International. The software of the system is integrated into the software of the automated process control system of the elevator and allows the operator to specify the components of the grain flow and the initial productivity of the flow-transport lines, select the flow-transport lines load control mode and select the flowtransport lines productivity setting mode in the current process situation, control the functioning of the loading optimization system. The results of a comparative analysis of the efficiency of load management during the unloading of railway cars by the operator "manually" and using an automated loading optimization system, conducted in 2020, showed the following: the average time of receive grain from railway cars, including idle time, decreased by 15\%; the average shipping performance without any downtime increased by 10\%. At the same time, there were no emergency stops of flow-transport lines transport equipment due to grain blockages during production tests and trial operation.

Ключові слова: прийом зерна, залізничний транспорт, поточно-транспортні лінії, продуктивність, енерговитрати, автомати-зована система оптимізації завантаження.

Keywords: grain reloading, railway transport, flow-transport lines, productivity, energy consumption, automated loading optimization system. 
http://www.atbp.onaft.edu.ua/

\section{Постановка задачі}

Компанія S-engineering входить до холдингу SE Group International i займає лідируючі позиції в області автоматизації технологічних процесів зернопереробної галузі включаючи в свої проекти інноваційні розробки. Зокрема, компанія займається розробкою інноваційних систем автоматичної оптимізації завантаження поточно транспортних ліній (ПТЛ) зернових терміналів. Метою таких систем є підвищення продуктивності і запобігання аварійних зупинок ПТЛ, зниження питомих витрат електричної енергії на перевантаження. В [1-3] розглянуті концепція побудови, результати досліджень та виробничих випробувань таких систем. Розробка системи включає кілька етапів основ-ним 3 яких є етап дослідження функціонування системи у виробничих умовах. На цьому етапі тестуються реалізовані алгоритми управління, остаточно перевіряється робота програмного забезпечення, розраховуються значення основних техніко-економічних показників роботи поточно транспортних ліній та визначається ефект від впровадження автоматизованої системи оптимізації завантаження (АСО3).

Ця стаття присвячена результатам дослідження ефективності функціонування АСОЗ ПТЛ прийому зерна 3 залізничного транспорту на елеваторі «МКХП Орексім» в м.Миколаїв.

\section{Призначення та функції АCO3}

АСОЗ ПТЛ прийому зерна з залізничного транспорту, впроваджена на зерновому терміналі компанії Орек-сім (рис. 1) $є$ інноваційною розробкою. Її мета - забезпечення прийому зерна одночасно з декількох залізничних вагонів, підвищення продуктивності ПТЛ, зниження енерговитрат на перевантаження, запобігання виникнення аварійних ситуацій, пов'язаних з завалами зерна в башмаках норій. ACO3 реалізує технологіï Leffol \& Senumac (L \& S), запатентовані SE Group International [4-5].

Технологія LEFFOL [4]: спосіб контролю ступеня завантаження конвеєра / Method of Loading Efficiency Control. Суть технології - підвищення точності вимірювання завантаження всіх типів конвеєрів продуктом в процесі його транспортування без використання спеціалізованих датчиків, тільки за рахунок вимірювання струму навантаження приводного електродвигуна.

Технологія SENUMAC [5]: спосіб автоматичного керування завантаженням поточно-транспортних ліній си-пучих матеріалів / S-engineering Useful Model Method of Automatic Control of Process Shipping line upload of granular materials. Суть технології - автоматичне керування завантаженням поточно-транспортної лінії, що до-зволяють їй досягти максимально можливу продуктивність лінії, близьку до критичної, при якій починається процес розвитку завалів зерна в її норі. При цьому алгоритм управління гарантує запобігання цих завалів.

Функції, які реалізує АСО3:

1. Автоматичний розрахунок початкової швидкості конвеєрів, які приймають зерно, для швидкого і безава-рійного виведення норії на задану продуктивність.

2. Автоматична стабілізація продуктивності загального потоку зерна (завантаження ПТЛ).

3. Автоматичне запобігання аварійних зупинок ПТЛ через розвиток завалів зерна у башмаках норій.

4. Автоматичне виведення продуктивності ПТЛ на максимально досяжну в поточних умовах величину.

5. Автоматична швидка (після команди оператора) зміна продуктивності ПТЛ до одного з заданих рівнів.

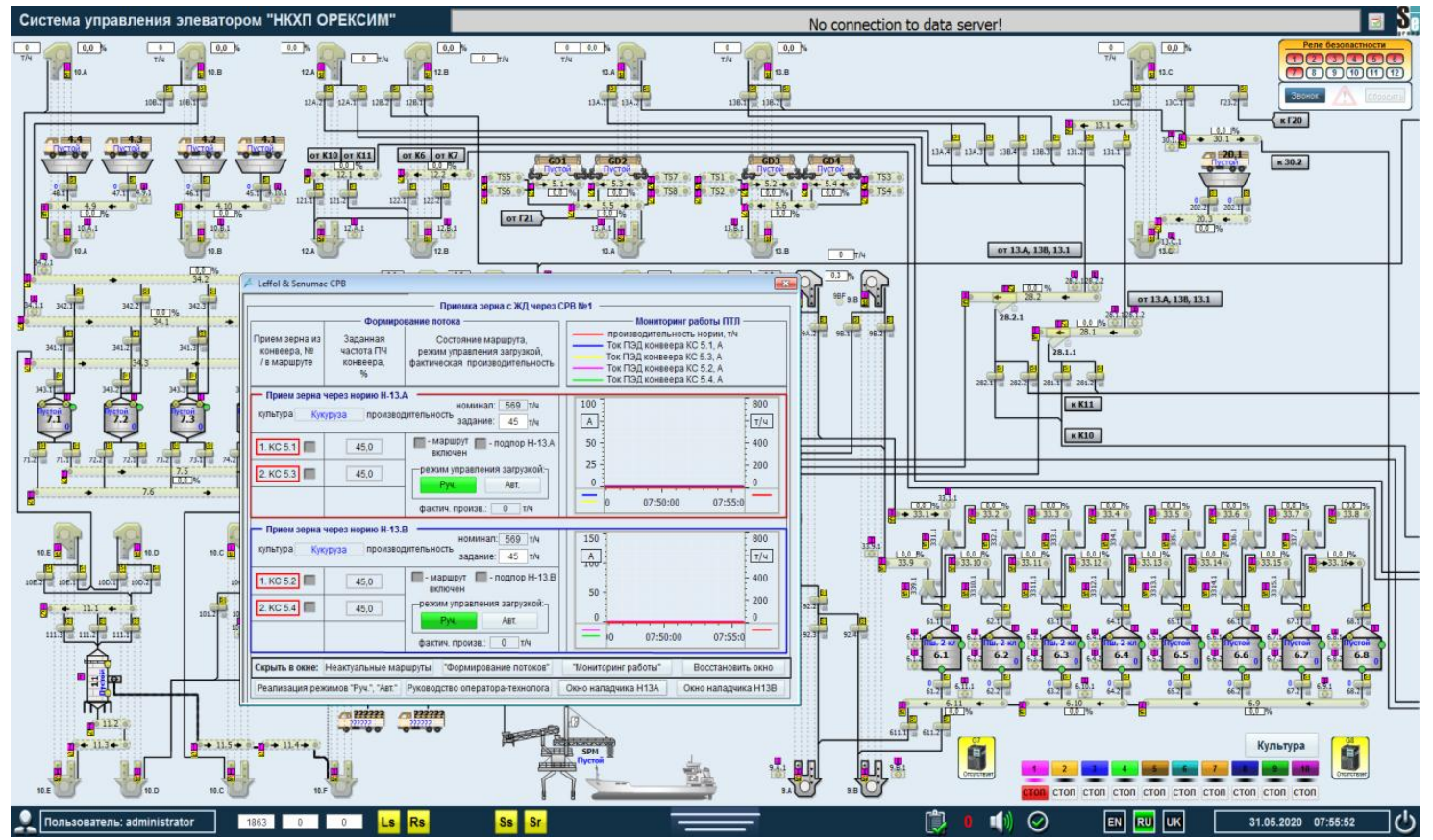

Рис. 1 - Вид основного екрану автоматизованого робочого місця оператора на зерновому терміналі компанії «МКХП Орексім» з фрагментом вікна графічного інтерфейсу для роботи з АСОЗ елеватора 
Для взаємодії оператора з АCO3 передбачено вікно графічного інтерфейсу оператора центрального диспетчерського пункту, див. рис.2, яке призначене для активації функцій, необхідних для управління процесом при-йому зерна $з$ залізничного транспорту в сформованій виробничої ситуації. Воно забезпечує, на рівні диспетчер-ського управління, виконання оператором його функцій контролю і управління процесом прийому зерна.

К функціям оператора при роботі з АСОЗ ПТЛ відносяться:

а) вибір (завдання) продуктивності ПТЛ;

б) контроль за функціонуванням АСО3.

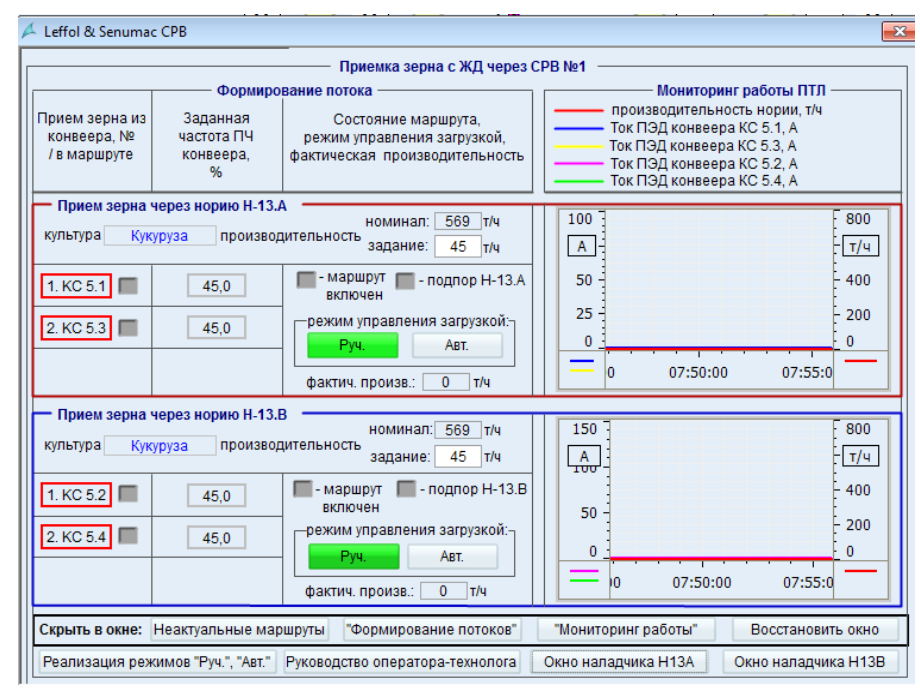

\section{Рис. 2 - Вид вікна графічного інтерфейсу оператора для його роботи з АСОЗ}

Вікно має дві функціонально орієнтовані частини, виділені спеціальної окантовкою з написами:

- ліва панель вікна: «Формування потоку»;

- права панель вікна: «Моніторинг роботи ПТЛ». «Формування потоку» є узагальненою назвою комплексу функцій управління і контролю, а саме: вибору режимів управління завантаженням ПТЛ, завдання продуктив-ності ПТЛ в поточній технологічної ситуації та контролю за функціонуванням АСОЗ.

\section{Результати виробничих випробувань АСО3}

Для оцінки ефективності АСОЗ ПТЛ в 2020 році був проведений порівняльний аналіз ефективності керування завантаженням ПТЛ при прийомі зерна оператором «вручну» (управління завантаженням ПТЛ оператор здійснював зі свого автоматизованого робочого місця) і з використанням АСОЗ. У кожному разі розрахунок те-хніко-економічних показників роботи ПТЛ прийому зерна виконувався за результатами прийому десяти вагонів. Нижче представлені кілька діаграм зміни продуктивності ПТЛ при прийомі зерна з залізничних вагонів з використанням АСОЗ, що дозволяють візуально оцінити динаміку зміни продуктивності.

На рис. 3 представлена діаграма зміни продуктивності ПТЛ при прийомі зерна під керуванням АСОЗ. 3 гра-фік видно, що система ефективно забезпечувала перехід з однієї заданої продуктивності на іншу з компенсацією діючих збурень і забезпечує запобігання завалу башмака норії зерном при перевантаженні (продуктивність більше 700 т / год) в пусковому режимі.

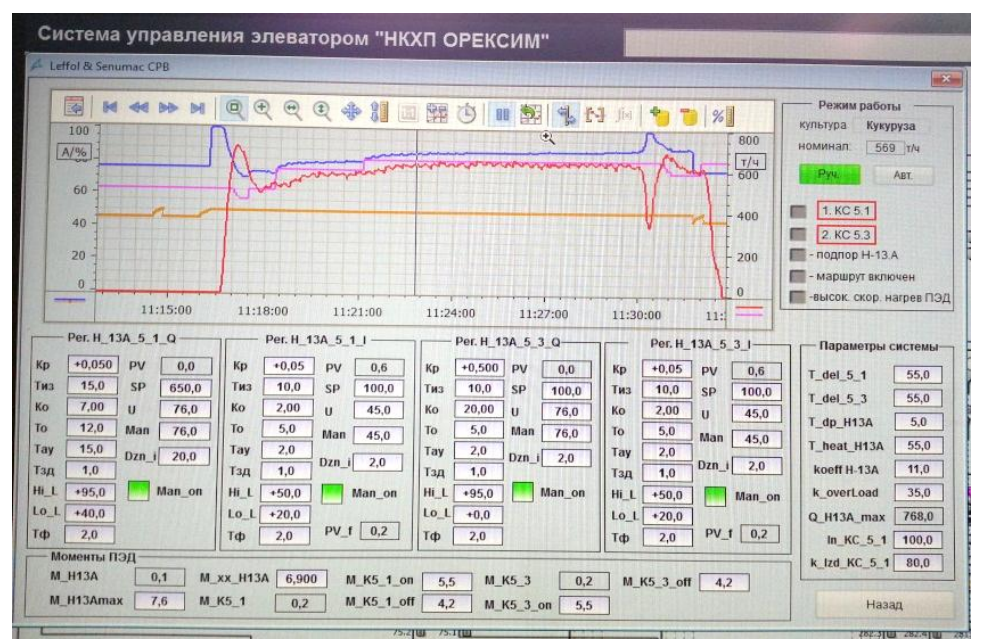

Рис. 3 - Вид вікна 3 діаграмою зміни продуктивності (т / год) ПТЛ при прийомі зерна з залізничних вагонів в «автоматичному» режимі із заданою продуктивністю 500, 600, i 650 т / год 
На рис. 4 представлена діаграма зміни продуктивності ПТЛ при прийомі зерна під керуванням АСОЗ з заданим значенням продуктивності 650 т / год. Видно, що система швидко (менше 1 хв.) виводить продуктивність на задане значення і забезпечує високу динамічну і статичну точність стабілізації.

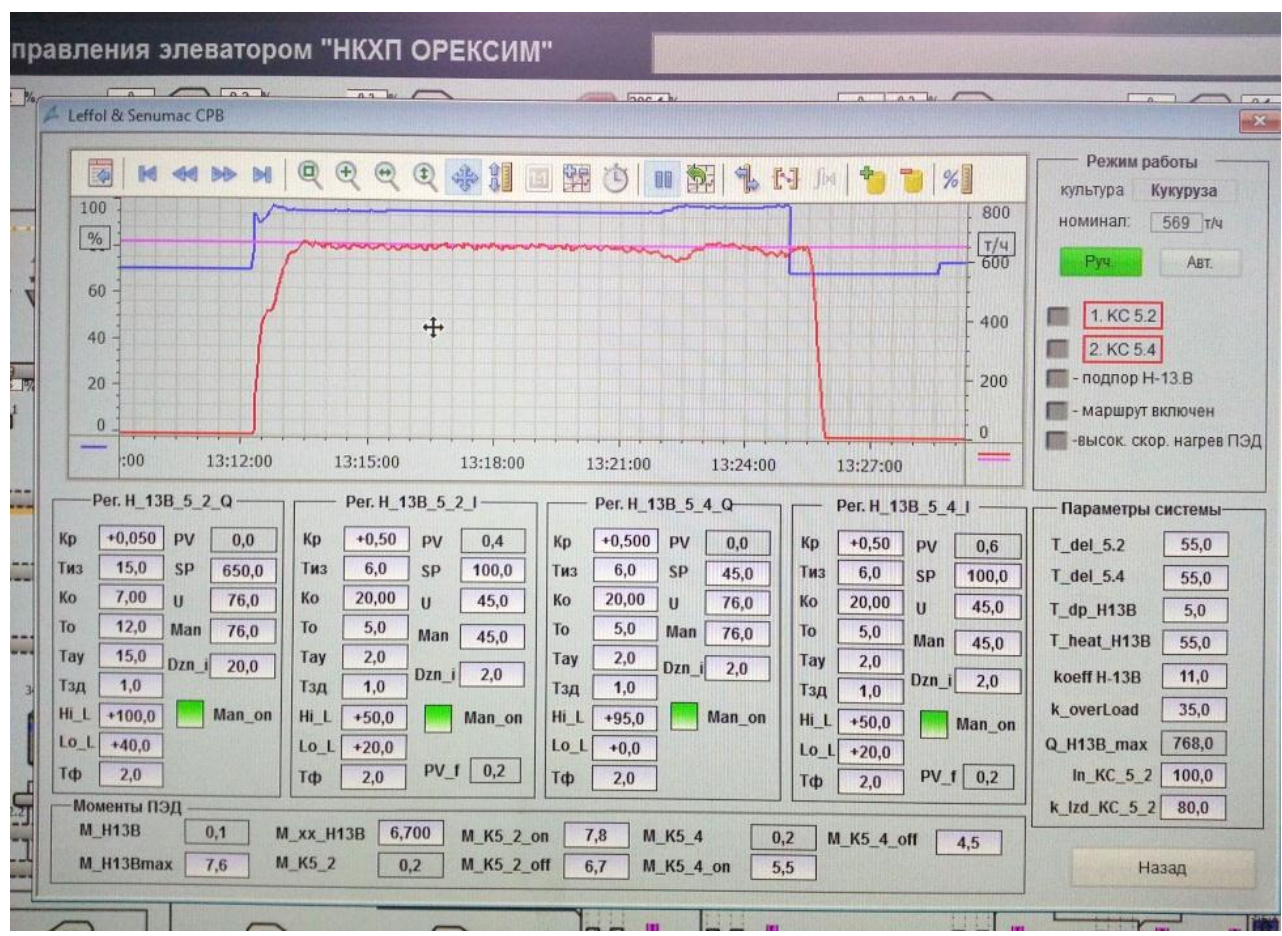

Рис. 4 - Вид вікна $з$ діаграмою зміни продуктивності (т / год) ПТЛ при прийомі зерна з залізничних вагонів в «автоматичному» режимі із заданою продуктивністю 650 т / год

На рис. 5 представлена діаграма зміни продуктивності ПТЛ при прийомі зерна під керуванням АСОЗ з заданим значенням продуктивності 650 т / год.

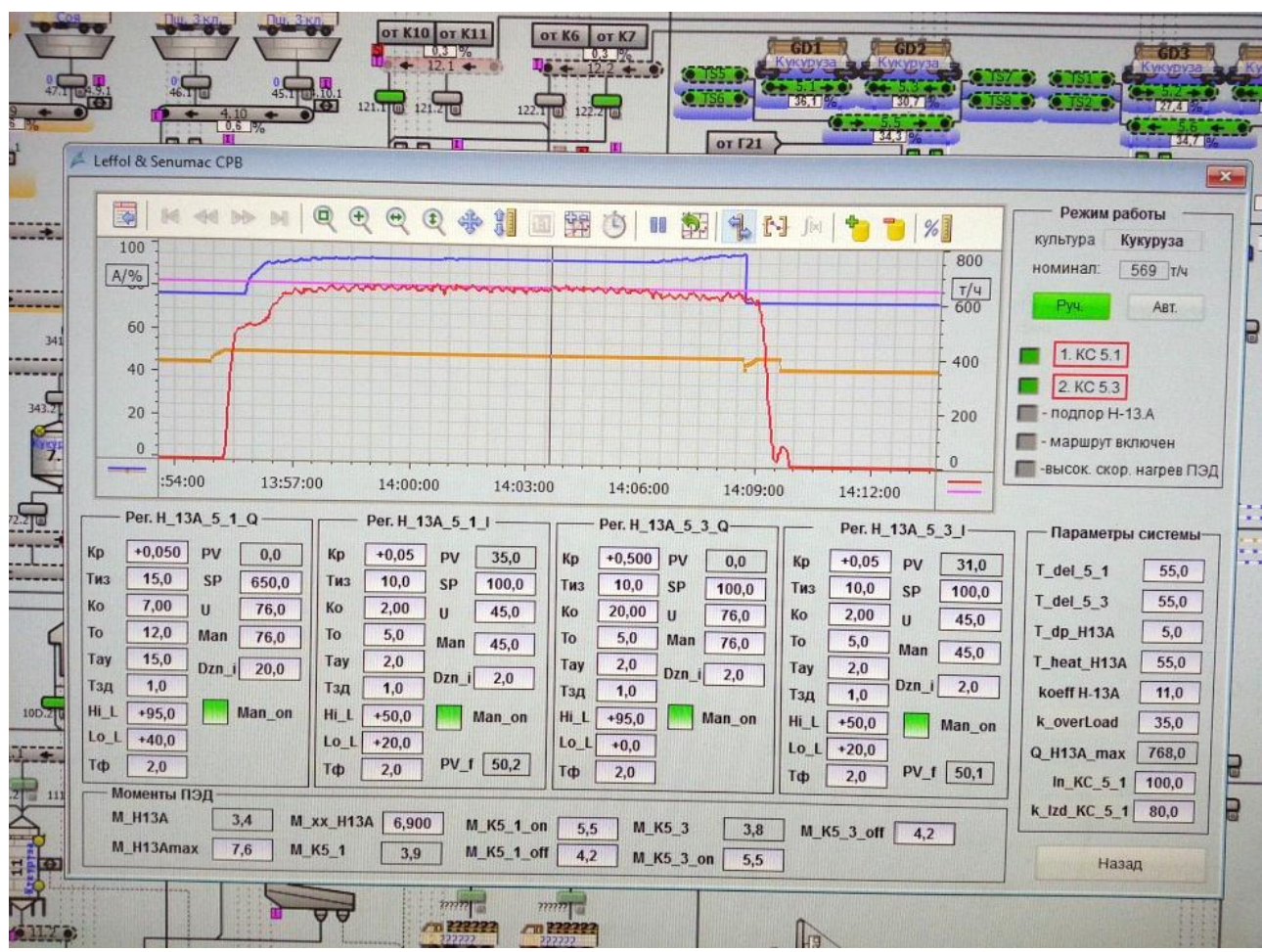

Рис. 5 - Вид вікна з діаграмою зміни продуктивності (т / год) ПТЛ при прийомі зерна з залізничних вагонів в «автоматичному» режимі із заданою продуктивністю 650 т / год 
Середня продуктивність досить висока (вище номінальної на 15\%), задане значення забезпечується навіть на етапі закінчення зерна в приймальному бункері.

\section{Висновок}

Результати порівняльного аналізу ефективності управління завантаженням ПТЛ при прийомі зерна 3 залізничних вагонів оператором «вручну» і з використанням АСО3, проведені в 2020 році, показали наступне:

- середній час прийому з урахуванням простоїв на зміну групи вагонів зменшилася на 15\%;

- середня продуктивність прийому без обліку простоїв збільшилася на 10\%.

При цьому, в сталих режимах АСО3 забезпечує середню продуктивність близько 650 т / год, в перехідних виведення ПТЛ на максимальне завантаження займає менше однієї хвилини. Останнє пояснюється тим, що перехідні процеси в АCO3 налаштовані так, щоб гарантова-но забезпечити безпечні (без завалів і аварійних відключень ПТЛ) і швидкі пускові режими ПТЛ в будь-яких виробничих ситуаціях.

Джерела підвищення ефективності роботи ПТЛ при застосуванні АCO3:

- скорочення часу роботи ПТЛ зі зниженою продуктивністю за рахунок безперервного управління швидкіс-тю конвеєрів які приймають зерно та стабілізують завантаження ПТЛ;

- максимізація продуктивності ПТЛ до іiі гранично допустимих значень, що визначаються паспортними характеристиками обладнання;

- скорочення часу роботи ПТЛ зі зниженою продуктивністю в режимах пуску ПТЛ та цілеспрямованої зміни ії продуктивності за рахунок значного скорочення часу перехідних процесів;

- гарантоване запобігання аварійних зупинок ПТЛ через їх перевантаження зерном і їх негативних наслідків.

\section{Список використаних джерел}

[1] Хобин В.А.Концепция эффективного управления производительностью поточно-транспортных линий при перегрузке зерна / В. А. Хобин, С. В. Шестопалов // Хранение и переработка зерна. - Днепропетровск, 2011. - № 10 (148). - C. 26-29.

[2] Шестопалов С. В. Оптимизация производительности процесса перегрузки зерна в условиях ограничения типа «аварийная ситуация» / С. В. Шестопалов, В. А. Хобин // XVIII Міжнарод. конф. 3 автомат. управління «Автоматика - 2011». - Львів, 2011. - С. 194-195.

[3] Кирьязов И. Н. Автоматизированная система оптимизации загрузки поточно-транспортных линий перегрузки зерна: итоги производственных испытаний / И. Н. Кирьязов, С. В. Шестопалов // Хранение и переработка зерна. Днепропетровск, 2013. - № 7 (172). - С. 43-46.

[4] Пат. на винахід 99525 Україна, МПК (2011.01), B65G 17/00, G01R 29/00. Спосіб контролю ступеня заван-таження конвеєра / Аннаев Б. С., Герасимов В. В., Хобин В. А., Кирьязов И.Н., Шестопалов С. В. и др.; власник ТОВ «СІнжинірінг». - № а201014455; заявл. 03.12.10; опубл. 25.05.12, Бюл. № 10. - 14 с.

[5] Пат. на винахід 95887 Україна, МПК (2011.01), B65G 17/00, B65G 47/46 (2006.01), B65G 65/42 (2006.01), G01G 11/12 (2006.01). Спосіб автоматичного управління завантаженням потоково-транспортної лінії сипких матеріалів / Аннаєв Б. С., Герасимов В. В., Хобін В. А., Кір’язов І. М., Шестопалов С. В. і ін.; власник ТОВ «С-Інжинірінг». № а201015861; заявл. 29.12.10; опубл. 12.09.11, Бюл. № 17. - 24 с.

\section{References}

[1] V. A. Khobin and S. V. Shestopalov, "Kontseptsiya effektivnogo upravleniya proizvoditelnostyu potochno-transportnyih liniy pri peregruzke zerna," Hranenie i pererabotka zerna, 10 (148), pp. 26-29, Oct. 2011.

[2] S. V. Shestopalov and V. A. Khobin, "Optimizatsiya proizvoditelnosti protsessa peregruzki zerna v usloviyah ogranicheniya tipa “avariynaya situatsiya," in VIII Mizhnar. konf. z avtomat. upravlinnia “Avtomatika - 2011”, LvIv, Ukraine, 2011, pp. $194-195$.

[3] I. N. Kiryazov and S. V. Shestopalov, “Avtomatizirovannaya sistema optimizatsii zagruzki potochno-transportnyih liniy peregruzki zerna: itogi proizvodstvennyih ispyitaniy," Hranenie i pererabotka zerna, 7 (172), pp. 43-46.

[4] B. S. Annaev et al., "Sposib kontrolu zavantazhennya konveera," Ukraine Patent na vynahid 99525, Biul. no. 10, 14 p., 25 May, 2012.

[5] B. S. Annaev et al., "Sposib avtomatichnogo upravlinnia zavantazhennyam potokovo-transportnoi linii sypkykh materialiv," Ukraine Patent na vynahid 95887, Biul. no. 17, 24 p., 12 Sept., 2011. 